\title{
¿Ciencias sociales para qué y para quién?
}

\author{
Andrés Pérez Baltodano \\ Politólogo;Universidad de Western Ontario, Canadá
}

\begin{abstract}
¿Estamos rompiendo con los parámetros de lectura que imponen las lógicas del poder? ¿̇De dónde surgen los temas que preocupan actualmente a las ciencias sociales? ¿̇urgen de una imaginación alerta y rupturista, o más bien de su vocación por ser eficazmente útiles a los problemas que imponen los proyectos de sociedad hoy dominantes?
\end{abstract}

El desarrollo de la teoría social latinoamericana ha mostrado una marcada tendencia a imitar el pensamiento de Europa y los Estados Unidos. Durante el siglo XVIII, las ideas de la Ilustración encendieron la imaginación de los criollos y les proporcionaron una base teórica para legitimar sus aspiraciones soberanas. El positivismo fue utilizado por las elites de la región en el siglo XIX como una consigna para lograr "el orden y el progreso" o, más bien, el orden sin progreso que les interesaba. En el siglo XX, la democracia liberal se esgrimió como un modelo normativo y, con frecuencia, como un disfraz para ocultar el "país real" que Octavio Paz encuentra sepultado bajo el "país legal" latinoamericano. Tras la Revolución Bolchevique, el Marxismo se transformó, para un importante sector político del continente, en la panacea de todos los males sociales. Más recientemente, el pensamiento neoliberal se ha convertido en la teoría y la ideología con que las élites latinoamericanas pretenden enfrentar los retos del siglo XXI.

A pesar de la tendencia imitativa que ha marcado el desarrollo del pensamiento y la teoría social en América Latina, la historia de la región muestra importantes brotes de originalidad que revelan el potencial creativo que yace bajo el peso de esta tendencia. La Pedagogía de la Liberación, la Teología de la Liberación y la Teoría de la Dependencia, son tres ejemplos de ese potencial. Hago referencia a estas contribuciones como "brotes de originalidad", ya que a pesar de su enorme relevancia no lograron institucionalizarse como verdaderas corrientes de pensamiento con la capacidad de modificar el rumbo de la pedagogía, la sociología y la teología latinoamericanas.

Después del colapso del llamado "socialismo real” y con la intensificación del fenómeno de la globalización, el estado de las ciencias sociales latinoamericanas es más deprimente que nunca. La crisis del Marxismo tuvo un fuerte impacto en el desarrollo del pensamiento crítico del continente. Acostumbradas a hacer interpretaciones textuales de las ideas de Marx, las ciencias sociales críticas latinoamericanas han sido incapaces de contextualizar 
esas ideas para identificar y analizar los errores que se cometieron con la importación acrítica de la teoría Marxista, y para intentar una recontextualización de esa teoría en el difícil siglo XXI que vivimos.

Por otra parte, el peso de la racionalidad instrumental del mercado durante las últimas tres décadas ha promovido la tecnocratización de las ciencias sociales de la región y un desarrollo teórico funcional a la racionalidad del mercado. Esa racionalidad se difunde a través de los circuitos de comunicación y control que condicionan los marcos normativos dentro de los cuales funcionan la comunidad académica y los centros de investigación de la región. Dentro de esos circuitos deben destacarse los que son controlados por la cooperación internacional que promueve la investigación en el campo de las ciencias sociales, y los que manejan los organismos financieros internacionales como el Banco Mundial y el Banco Interamericano de Desarrollo (BID). El poder de estos organismos ha logrado transformar a muchos de los más talentosos investigadores de la región, en consultores que trabajan a partir de los términos de referencia que esas organizaciones establecen.

Organismos como el Banco Mundial y el BID no solamente trabajan en el campo de las finanzas, sino también en la construcción de discursos y representaciones de la realidad. Esos organismos, para ser más preciso, laboran en la generación de visiones e interpretaciones sociales que son afines a sus objetivos institucionales y, por lo tanto, a la racionalidad del mercado. El peso cada vez mayor que ellos tienen en el mundo de las ciencias sociales se ha traducido en un alto grado de homogenización de las perspectivas teóricas desde las que se analizan los problemas que afectan a las sociedades de la región. De esa manera se ha logrado consolidar una forma de practicar las ciencias sociales que guarda mucha similitud con la práctica del embedded journalism, impuesta por el gobierno de los Estados Unidos durante la guerra de Irak.

Como es bien conocido, la práctica del embedded journalism -la incorporación física de los hombres y las mujeres de prensa a las unidades de combate- resolvió el problema que para el gobierno de los Estados Unidos significaba la libre movilidad de los periodistas en las zonas de conflicto, y las posibilidades que esa movilidad genera para que los que cubren las guerras de ese país puedan adoptar múltiples perspectivas para informar al mundo, incluyendo la de los ciudadanos de los países invadidos y atacados por los Estados Unidos. La famosa foto de la niña vietnamita, corriendo desnuda después de recibir un baño de Napalm durante el bombardeo de la villa de Trang Bang, a 25 kilómetros de Saigón, el 8 de Junio de 1972, es uno de los ejemplos más reveladores del periodismo que Washington logró evitar en su más reciente guerra. Esa foto acercó al público estadounidense y del resto del mundo a la perspectiva de los que sufren, modificando percepciones y generando resistencia frente a la guerra en Viet Nam.

Un fenómeno similar al del embedded journalism es el de las ciencias sociales latinoamericanas que operan hoy empotradas en la racionalidad del mercado que propagan y reproducen los organismos financieros internacionales, la cooperación internacional, los think tanks y hasta las universidades del Norte. La influencia de esas organizaciones ha facilitado la imposición de una perspectiva teórica que proyecta una visión no-conflictiva de la política que sirve para consolidar un orden social congruente con las necesidades 
del mercado. Esa perspectiva oculta el costo social, político y cultural que se deriva del desarrollo del neoliberalismo en la región.

\section{La perspectiva neoliberal y la visión no-conflictiva de la política}

La visión no-conflictiva de la política ha sido analizada lúcidamente por Chantal Mouffe ${ }^{1}$ para hacer referencia a algunas corrientes de pensamiento en el Norte que asumen que la posmodernidad ha puesto fin a la confrontación de proyectos sociales y políticos hegemónicos representativos de intereses contradictorios. Las diferencias que todavía existen, o las nuevas que han surgido a partir de la crisis de la modernidad-dice ese discurso posmoderno y neoliberal-son marginales y pueden ser resueltas mediante el diálogo.

Chantal Mouffe muestra como la visión no-conflictiva de la política es ilusa, ya que no resuelve, sino que simplemente niega las principales tensiones y contradicciones que siguen formando parte de la sociedad postmoderna, independientemente de que la forma y las expresiones de esas tensiones y contradicciones hayan cambiado. La visión no-conflictiva de la política también es peligrosa -dice Mouffe- porque las tensiones y contradicciones sociales no encuentran una salida política dentro del marco de esa visión. Más bien, tienden a manifestarse en expresiones no políticas y no democráticas del conflicto social, como el racismo.

La visión no-conflictiva de la política se ha impuesto en las ciencias sociales del Sur creando un ambiente intelectual en el que el clásico tema del "orden social" -que en las tradiciones sociológicas de Max Weber y Karl Marx obliga a pensar en el "conflicto social” como el otro lado de la moneda del "orden"-, ha sido sustituido por el inútil y estéril concepto de la "gobernabilidad" que impone una visión normativa de la sociedad que es funcional al desarrollo del mercado.

Lo contrario de la gobernabilidad no es el conflicto político o las transformaciones estructurales que hasta hace poco eran consideradas como elementos normales de la dinámica histórica de cualquier sociedad. Lo contrario a la gobernabilidad es el caos y el desorden que deben evitarse a cualquier precio porque perturban la normalidad que exige el desarrollo del capital.

El concepto de la gobernabilidad se apoya en el concepto de la "sociedad civil" que sirve para describir las organizaciones de representación y participación que contribuyen a mantener y reproducir el orden que demanda la sociedad de mercado. El Banco Mundial² define el concepto de sociedad civil como "una amplia gama de organizaciones no gubernamentales y sin fines de lucro que están presentes en la vida pública, expresan los intereses y valores de sus miembros y de otros, según consideraciones éticas, culturales, políticas, científicas, religiosas o filantrópicas". Y agrega: "Por lo tanto, el término organizaciones de la sociedad civil abarca una gran variedad de organizaciones: grupos comunitarios, organizaciones no gubernamentales, sindicatos, grupos indígenas, organizaciones de caridad, organizaciones religiosas, asociaciones profesionales y fundaciones".

1 MOUFFE, C. (2005) On the Political. London/New York: Routledge.

2 BANCO MUNDIAL (2008) "Definición de Sociedad Civil”, http://web.worldbank.org 
Nótese que todos los intereses de la sociedad están formalmente incluidos en la definición de sociedad civil del Banco Mundial. ¿En qué se diferencia entonces el concepto de "sociedad civil" del viejo concepto de "sociedad" que antes se conceptualizaba como una unidad formada por clases sociales o por élites y masas, en relaciones de conflicto? La diferencia radica en que el concepto de sociedad civil que promueven los organismos financieros internacionales representa una sociedad armónica -o la ilusión de una sociedad armónica-, compuesta por actores que operan dentro de un consenso básico que transforma todos sus conflictos en diferencias marginales que supuestamente pueden ser resueltas mediante el uso de "mecanismos de concertación" que están diseñados para no cuestionar el régimen económico imperante.

Así pues, la democracia que promueve el BID es un modelo formal de resolución de conflictos marginales que opera dentro de un consenso social estructurado a partir de la lógica y los valores del capital. Ese consenso, en otras palabras, no surge de la confrontación y el balance de los intereses y las aspiraciones sociales que coexisten dentro de un espacio político nacional. El consenso social que promueve el BID se define de antemano; es decir, precede a la constitución de la sociedad civil y de los mecanismos de participación ciudadana. En otras palabras, la sociedad civil y la participación ciudadana no se organizan para definir un modelo de sociedad que responda a las tensiones y contradicciones que generan las aspiraciones y necesidades de sus miembros. Se organiza para legitimar y hacer funcional el modelo de economía y sociedad neoliberal. Así, el Estado deja de ser una arena de conflicto para convertirse en un mecanismo institucional que, junto con la sociedad civil, funciona para reproducir el modelo capitalista neoliberal.

En síntesis, las tensiones y contradicciones que se derivan de la organización y distribución del poder en la sociedad son disimuladas con la promoción de una visión no-conflictiva de la política, y con la institucionalización de mecanismos de participación política controlada, que rechazan y deslegitiman cualquier forma de "confrontación". Lo dice expresamente el BID en su Estrategia para Promover la Participación Ciudadana en las Actividades del Banco (2004): "La modernización del Estado, que es una de las áreas prioritarias de la estrategia institucional del Banco, implica un proceso complementario y recíproco de fortalecimiento de la sociedad civil. La adopción de este enfoque cooperativo y complementario entre Estado y sociedad civil, alejado de visiones confrontacionales, y sus implicancias en cuanto a la participación de los ciudadanos en las actividades operacionales del Banco, es particularmente relevante si se toma en consideración que, derivado de las condiciones políticas que prevalecieron en décadas anteriores, ha existido entre ambos una relación de limitada cooperación y en algunos casos de desconfianza e incomprensión”3.

\section{Una nueva perspectiva}

La revitalización de las ciencias sociales de la región demanda un cambio de perspectiva y, más concretamente, su desempotramiento de la lógica neoliberal que hoy domina

3 BANCO INTERAMERICANO DE DESARROLLO (2004). Estrategia para Promover la Participación Ciudadana en las Actividades del Banco. Washington: BID. 
su desarrollo. Para lograr ese objetivo, es necesario promover, primero, una ruptura epistemológica que le permita a las ciencias sociales apropiarse de lo que Rubén Darío llamó "el poder demiúrgico de la palabra”. Segundo, una reorientación teórica que permita la generación de un conocimiento social más auténtico. Y tercero, un posicionamiento ético que le permita a las ciencias sociales ver y percibir el mundo y la realidad social desde la posición que ocupan los "condenados de la tierra".

El papel de las ciencias sociales es hacer sentido de la realidad. Al hacerlo, el conocimiento social desarrolla el poder para cambiar esa misma realidad ${ }^{4}$. Las ciencias sociales, desde esta perspectiva, participan en la construcción de la historia y de la realidad. Lo hacen, revelando, distorsionando u ocultando las diferentes dimensiones de la condición humana.

Si aceptamos que la realidad social es, en gran medida, una construcción teórica y conceptual, tenemos que aceptar que para que el conocimiento sea capaz de contribuir a la solución de los problemas profundos de las sociedades latinoamericanas, debe ser auténtico; es decir, debe nutrirse de la vida y la historia de esas sociedades. En este sentido puede decirse que el conocimiento generado por las ciencias sociales europeas ha sido auténtico, porque se ha nutrido del desarrollo histórico del "viejo continente" y ha respondido a ese desarrollo.

Desdichadamente, la inautenticidad ha sido una de las principales características del conocimiento generado por las ciencias sociales de la región. Los conceptos, modelos y teorías generados por Europa y los Estados Unidos han funcionado como el prisma a través del cual los investigadores latinoamericanos han tratado de elucidar el sentido de la realidad social de la región. Esto explica que, al igual que en los países del Norte, el punto central de la controversia académica en América Latina durante la segunda mitad del siglo $\mathrm{XX}$, haya sido la confrontación entre la teoría marxista y la teoría social "burguesa". El trasfondo invisible de esta discusión fue la historia de Europa, ya que la historia real de la región -la historia de Estados que han sido incapaces de crear naciones y de naciones incapaces de producir Estados-naciones; la historia profunda de los pueblos indígenas y afrodescendientes; la historia ignorada del mestizaje y su cultura; y otras- se mantuvo y se mantiene escondida en una suerte de oscuridad preteórica.

El ocultamiento de la realidad profunda latinoamericana ha sido facilitada por la tendencia que ha existido en las ciencias sociales de la región a interpretar textualmente las ideas generadas por Europa y los Estados Unidos. La interpretación textual de las ideas se basa en el supuesto de que el texto -marxista o neoliberal- es el objeto "único" y "autosuficiente" de investigación. Desde esta perspectiva, como dice David Boucher, "la lectura acuciosa y repetida de los textos, una y otra vez, se considera como un medio adecuado para desentrañar su significado" . El contexto histórico en que aparecen las ideas, o se ignora, o se trata marginalmente. En consecuencia, el estudio de las ideas desemboca en la mistificación de libros y autores, considerados poseedores de cualidades trascendentales y suprahistóricas. 
La asimilación textual (descontextualizada) de la teoría social eurocéntrica, y de la base conceptual que ésta utiliza, se ha intensificado en las últimas décadas debido a la influencia que tienen los organismos de generación cultural del Norte en la producción de conocimiento social en la región. Tal como se señaló antes, la adopción textual y, por lo tanto ahistórica y acrítica de la teoría neoliberal, ha llevado a las ciencias sociales latinoamericanas a legitimar el uso de conceptos que, como la gobernabilidad, la sociedad civil, la cohesión social y otros, ocultan más de lo que revelan.

El redimensionamiento teórico que se necesita para desempotrar las ciencias sociales latinoamericanas de la lógica instrumental del mercado que hoy las domina, implica promover activamente la autenticidad del conocimiento social. Implica, en otras palabras, acercar la teoría a la realidad de la América Latina que viven los millones de personas que padecen las consecuencias de la pobreza y la exclusión social en la región.

Este redimensionamiento teórico, a su vez, requiere un posicionamiento ético. Hablar de ética en el contexto de las ciencias sociales es hacer referencia al sistema de valores y normas que los estudiosos de la región utilizan para definir el sentido de lo que es relevante e irrelevante, auténtico e inauténtico, en sus agendas de investigación. Ese sistema de valores y normas está condicionado, como se señaló antes, por la racionalidad instrumental del mercado que se difunde a través de las universidades, la cooperación internacional, y los organismos financieros internacionales. El cambio de perspectiva que demanda la revitalización de las ciencias sociales implica asumir una posición ética frente a esa racionalidad. Esta es una tarea difícil, pero necesaria y posible.

La racionalidad del mercado condiciona, pero no necesariamente determina, la ética de los individuos que la integran. En otras palabras, la posición de un actor frente a cualquier moralidad institucionalizada, se establece casi siempre dentro de un espacio ético de libertad que le permite a ese actor decidir el tipo de relación que va a establecer con los valores que legitiman las estructuras de poder existentes. De lo contrario no hubiese existido un Marx, o una Rosa Luxemburgo, o un Mariátegui. Ejemplos como estos deben orientar el desarrollo de unas ciencias sociales comprometidas con la búsqueda de nuevos y más justos modelos de vida social. Esa búsqueda no puede ser utópica, si como utópicos se denominan aquellos proyectos sociales que no reconocen límites a la capacidad humana para perfeccionar su historia; pero tampoco puede ser pragmática, si por pragmatismo se entiende la tendencia a asumir que existe una realidad que es independiente de la acción y del pensamiento y ante la cual hay que postrarse en homenaje y reverencia.

Entre la utopía y el pragmatismo existe el mundo de la realidad que se construye socialmente mediante la ampliación mental y práctica del marco de posibilidades históricas que definen los límites temporales de lo posible. Este es el mundo de la acción reflexiva; es decir, de la acción orientada por una teoría social auténtica que se nutre de la realidad para construir nuevas realidades. 